\title{
Cross-cultural translation and validation of the Hindi version of the intermittent and constant osteoarthritis pain scale in knee osteoarthritis patients
}

\author{
Ovijit Baidya ${ }^{1 *}$, Rati Prabhakar ${ }^{2}$, Manni Wadhwa ${ }^{3}$ and Prosenjit Baidya ${ }^{1}$ \\ ${ }^{1}$ MPT Orthopaedics, Lovely Professional University, India
}

${ }^{2}$ Associate Professor, Department of Physiotherapy, Adesh University, Bathinda, India

${ }^{3}$ Assistant Professor, Department of Physiotherapy, Lovely Professional University, India

Submission: January 13, 2018; Published: February 12, 2018

*Corresponding author: Ovijit Baidya, MPT (Orthopaedics), Lovely Professional University, India, Email: cn_bihs_2012@yahoo.com

Abstract

Background: Intermittent and constant osteoarthritis pain (ICOAP) scale is a new outcome measure scale for measuring pain in knee osteoarthritis which is not available in Hindi language. Main objective of this study was to analyse the reliability, validity and responsiveness of the Hindi version of ICOAP questionnaire.

Methods: Translation and cross-cultural adaptation of the scale was done following standardized protocol. Reliability and validity of the Hindi ICOAP was checked by administrating the scale twice along with Hindi KOOS scale with an interval of 2- 4 days. Responsiveness of the scale was assessed after 4 weeks of physiotherapy treatment for knee osteoarthritis. For reliability and validity analysis test- retest reliability, internal consistency and construct validity were analysed and for responsiveness testing, effect size (ES) and standardized response mean (SRM) were calculated.

Results: The Hindi ICOAP showed good internal consistency with Cronbach's $\alpha(0.817-0.912)$ and test-retest reliability (ICC $=0.973-0.984)$ for ICOAP scores. Correlation of ICOAP constant pain was found (0.68 and 0.68), for ICOAP intermittent pain (0.78 and 0.79) and for ICOAP total pain $(0.78$ and 0.80$)$ with KOOS pain and symptom score respectively. Responsiveness analysis of Hindi ICOAP scores found ES= $(2.63,2.46,2.72)$ and $\mathrm{SRM}=(3.37,4.02,4.38)$ for constant pain, intermittent pain subscale and total pain scale respectively confirming the responsiveness of the scale.

Conclusion: The Hindi ICOAP questionnaire is a reliable and valid instrument and it can successfully detect the change in patient's condition after 4 weeks of physiotherapy for knee osteoarthritis.

Keywords: Knee osteoarthritis; Reliability; Responsiveness; Validity

\section{Introduction}

Osteoarthritis $(\mathrm{OA})$ is the most common degenerative joint disease. It mostly affects the large joints of the body that take part in load distribution [1]. Hip and knee osteoarthritis are the most frequently seen chronic rheumatic disease resulting pain and associated disability in most countries around the world. It is the second most common rheumatological condition and most frequent joint disease in India with prevalence rate of $22 \%$ to $39 \%$ $[2,3]$. As the life expectancy of general population is increasing in India, the age-related pain and disability is increasing as well. The disease cannot be cured because of its irreversible nature so most of the attention is given on preventing the risk factors. Reasons behind the difference in prevalence is because of the differences in heredity, geographical background, lifestyle, daily activity, age and occupation $[2,4]$.

Knee joint is the most commonly affected structure in OA patients worldwide. Among the knees lateral, medial and patellofemoral compartment, any one or more compartments can get involved [4,5]. As the prevalence of knee OA increases with age it can have marked impact on the quality of life of individual's thus threatening community health [6]. At present there are several knee joint specific outcome measure tools attainable for measuring patients condition who are suffering from knee OA. Among them most commonly used tools are Knee Injury and Osteoarthritis Outcome Score (KOOS), The Intermittent and Constant Osteoarthritis Pain measure (ICOAP), The Western Ontario and McMaster Universities Osteoarthritis Index (WOMAC) [7]. ICOAP is a relatively new scale introduced to measure two distinct types of pain, a constant pain and an intermittent pain in knee OA. Researchers have found that the ICOAP English version scale is reliable and valid for measuring knee OA pain $[7,8]$. As the use of ICOAP scale is increasing day by day, medical practitioners prefer this scale because of its easy applicability and reliability. 
For proper administration, different educational background and cultural diversities in general population, ICOAP scale has already been translated and cross culturally adapted into several languages. But still no translated version of the scale is available in any Indian language. As Hindi is the most widely spoken language in India at least Hindi version of ICOAP should be available for applying the scale in Indian knee OA population. This will be beneficial for Indian patients who do not understand English because they will be able to express their pain in a better way. So, the current study will evaluate the reliability, validity and responsiveness of the Hindi version of ICOAP questionnaire in Indian Hindi speaking population.

\section{Material \& Methods}

The translation and cross-cultural adaptation process were conducted following standardized protocol for translation and cross-cultural adaptation of the ICOAP scale [1]. The process includes the following steps i.e. firstly, independent translation of the original scale into Hindi language by two independent native Hindi speakers. Then consensus meeting was organized among the translators to obtain a single preliminary translated version. Backward translation of the preliminary version was done by an independent English speaker. Then final version was formulated in a multidisciplinary agreement board and pretesting of the final version was done with 15 Hindi language speaking knee OA patients. A total of 88 subjects were included by using convenient sampling among which 30 subjects participated in the validity and reliability study and the rest 58 participated in the responsiveness study. Patients were taken from Outpatient department, Uni-Hospital (Department of Physiotherapy, Lovely Professional University, Punjab, India); Outpatient Department, Phagwara (Department of Physiotherapy, LPU); Outpatient Department (Sri Vishwakarma Charitable Hospital, Phagwara, Punjab).

The study was approved by the Departmental Ethical Committee of Lovely Professional University, India. The study was conducted during the period of March 2016 to March 2017. Osteoarthritis patients pre-diagnosed by Orthopedician were further assessed according to ACR criteria and were included in this study [9]. Patients were excluded if they had secondary arthritis due to inflammatory condition like rheumatoid arthritis [10], presence of any hip or ankle pathology, knee joint contracture or deformity or any surgical procedure/injury on either lower limb in past six months [2]. Informed consent was taken from all the participants. After that participants were asked to complete the ICOAP and KOOS questionnaire Hindi version. For reliability and validity analysis participants were asked to answer the ICOAP and KOOS questionnaire Hindi version second time after an interval of 2-4 days [11].

The responsiveness of Hindi version of ICOAP was checked along with Hindi KOOS scale in knee osteoarthritis patients undergoing physiotherapy treatment. Participants were randomly divided into two groups. All the patients were treated with 4 weeks of physiotherapy treatment. Pre and post treatment outcome measure of group 1 was taken on Hindi ICOAP and of group 2 was taken on Hindi KOOS. Collected data was then sent for statistical analysis. Test retest reliability was analysed using Intra-class Correlation Coefficient (ICC). An ICC of $\geq 0.70$ was considered acceptable. Cronbach's alpha was used to assess the internal consistency of Hindi ICOAP questionnaire [12]. Construct validity was analysed by using Spearman's correlation coefficient $(r)$ to find out the correlation between Hindi ICOAP and KOOS scores.

The correlations were judged as poor $(\mathrm{r}=0-0.30)$, weak ( $\mathrm{r}$ $=0.31-0.50)$, moderate $(r=0.51-0.70)$, good $(r=0.71-0.90)$ or excellent $(r=0.9-1.0)$ [13]. For responsiveness analysis effect size (ES) of 4 weeks of physiotherapy and standardized response mean (SRM) were calculated for both the pain measures. The ES was calculated with the following formula: (mean change in scores)/SD of the pre-treatment score and the SRM was calculated with the following formula: (mean change in scores)/SD of the change in score. Values of 0.80 or higher were considered to be indicative of high responsiveness [14]. The presence of floor and ceiling effects were also analysed [8]. All statistical analysis was conducted using SPSS 20.0 for Windows (SPSS Inc., Chicago, IL, USA).

\section{Results}

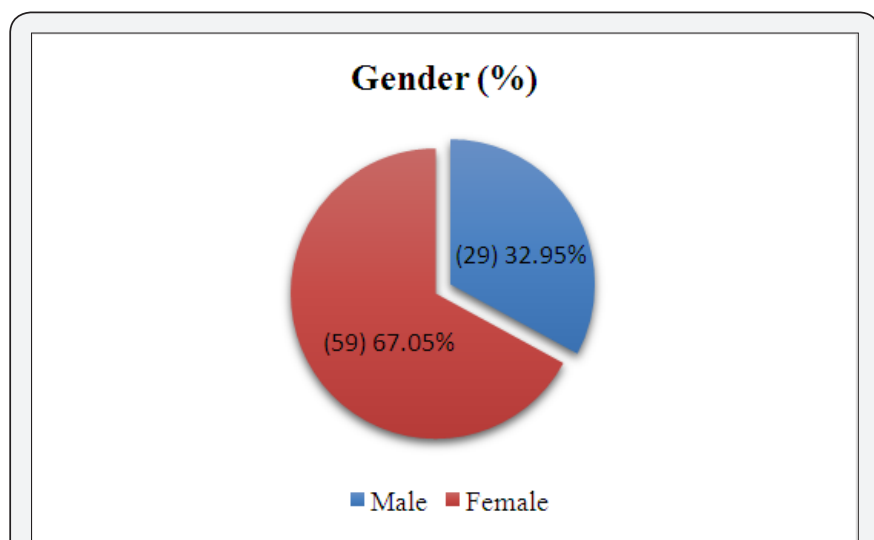

Figure 1: Gender distribution showing the percentage of male and female gender, indicates that among the patients $67.05 \%$ were female and $32.95 \%$ were male.

Table 1: Demographic characteristics of the participants.

\begin{tabular}{|c|c|c|}
\hline Characteristics & Mean & SD \\
\hline Age (years) & 59.9 & 7.027 \\
\hline Weight $(\mathrm{Kg})$ & 71.69 & 13.38 \\
\hline Height $(\mathrm{m})$ & 1.63 & 0.075 \\
\hline BMI $(\mathrm{Kg} / \mathrm{m} 2)$ & 27.14 & 4.86 \\
\hline
\end{tabular}

\section{SD: Standard Deviation; BMI: Body Mass Index}

A total of 88 subjects ( 59 females and 29 males) were included in the study. Table 1 shows the demographic characteristics of the participants (Figures $1 \& 2$ ). The mean age of the study sample $(n=88)$ was $59.9 \pm 7.027$ years with males $(32.95 \%)$ and 


\section{Orthopedics and Rheumatology Open Access Journal}

females (67.05\%). The mean BMI of the patient was $27.14 \pm 4.86$ $\mathrm{Kg} / \mathrm{m}^{2}$ and percentage of affected knee was $60.23 \%$ for both knee, $23.86 \%$ for right knee and $15.9 \%$ percent for left knee.

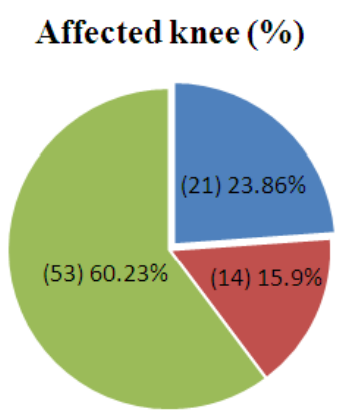

- Right $=$ Left $=$ Both Side

Figure 2 : Distribution of affected knee showing the percentage of affected knee where in $60.23 \%$ case both knee was affected, $15.9 \%$ had affected left knee and $23.86 \%$ had affected right knee.
Table 2 shows the reliability analysis of the Hindi ICOAP subscales and total pain scale. Based on the results of paired comparisons after 2-4 days the participants responses did not change significantly for the subscales and total pain scale. The Cronbach's $\alpha$ values were calculated to be $0.912,0.85$ and 0.817 for total pain, constant pain and intermittent pain respectively. Test-retest reliability was found to be ICC $=0.984$ for total score, ICC $=0.976$ for constant pain subscale and ICC $=0.973$ for intermittent pain subscale.

After 1st administration all participants were assessed again after 2- 4 days for the second time. Statistically significant negative correlations were found for ICOAP constant pain with KOOS pain $(-0.68)$ and with KOOS Symptoms $(-0.68)$. For ICOAP intermittent pain scale it was $(-0.78$ and -0.79$)$ and for ICOAP total pain scale it was $(-0.78$ and -0.80$)$ with KOOS pain and symptom score respectively (Table 3 ). For all the Hindi ICOAP subscales and total scale ES and SRM value was more than 0.80 and was ES=2.46-2.72 and SRM=3.37-4.38 (Table 4). Similarly, for all the Hindi KOOS subscales ES and SRM value was more than 0.80 and was $E S=1.67-3.32$ and SRM $=2.8-5.24$ (Table 5).

Table 2: The results for the ICOAP reliability study.

\begin{tabular}{|c|c|c|c|c|c|}
\hline Variables & $\begin{array}{c}\text { First } \\
\text { Administration } \\
\text { Mean (SD) }\end{array}$ & $\begin{array}{c}\text { Second } \\
\text { Administration } \\
\text { Mean (SD) }\end{array}$ & $p$ value & $\begin{array}{l}\text { Intra-class } \\
\text { correlation } \\
\text { coefficient }\end{array}$ & $\begin{array}{c}\text { Cronbach's } \\
\text { Alpha }\end{array}$ \\
\hline Constant pain score & $36.6(14.3)$ & $36.3(15.1)$ & $0.5725^{*}$ & 0.976 & 0.85 \\
\hline $\begin{array}{l}\text { Intermittent pain } \\
\text { score }\end{array}$ & $44.5(12.9)$ & $44.7(12.5)$ & $0.7777^{*}$ & 0.973 & 0.817 \\
\hline Total pain score & $40.9(13.1)$ & $41(13.7)$ & $0.8666^{*}$ & 0.984 & 0.912 \\
\hline
\end{tabular}

*Pair comparison is significant at the 0.05 level (2-tailed).

Table 3: Spearman correlation coefficient between ICOAP and KOOS scores.

\begin{tabular}{|c|c|c|c|}
\hline & $\begin{array}{c}\text { ICOAP } \\
\text { Constant pain scale }\end{array}$ & $\begin{array}{c}\text { ICOAP } \\
\text { Intermittent pain scale }\end{array}$ & $\begin{array}{c}\text { ICOAP } \\
\text { Total pain scale } \\
\end{array}$ \\
\hline Variables & $\begin{array}{l}\text { Spearman } \\
\text { correlation } \\
\text { coefficient }\end{array}$ & $\begin{array}{l}\text { Spearman } \\
\text { correlation } \\
\text { coefficient }\end{array}$ & $\begin{array}{l}\text { Spearman } \\
\text { correlation } \\
\text { coefficient }\end{array}$ \\
\hline KOOS Pain & $-.68 * *$ & $-.78 * *$ & $-.78 * *$ \\
\hline KOOS Symptoms & $-.68 * *$ & $-.79 * *$ & $-.80 * *$ \\
\hline
\end{tabular}

${ }^{* *}$ Correlation is significant at the 0.01 level (2-tailed).

ICOAP: Intermittent and constant osteoarthritis pain; KOOS: Knee injury and osteoarthritis outcome score.

Table 4: ICOAP pain measures at baseline and 4 weeks post Physiotherapy treatment - Mean change, ES, SRM.

\begin{tabular}{|c|c|c|c|c|}
\hline \multirow{2}{*}{ Measure } & \multicolumn{2}{|c|}{ Mean (SD) } & \multirow{2}{*}{$\begin{array}{c}\text { Mean (SD) } \\
\text { Change* }\end{array}$} & \multirow{2}{*}{ ES } \\
\cline { 2 - 5 } & Pre treatment & Post treatment & $33.45(9.92)$ & 2.63 \\
\hline Constant pain & $37.93(12.71)$ & $4.08(6.17)$ & $41.21(10.24)$ & 2.46 \\
\hline Intermittent pain & $55.87(16.75)$ & $14.66(9.62)$ & $37.67(8.59)$ & 4.02 \\
\hline Total pain & $47.73(13.86)$ & $10.05(6.64)$ & 4.38 & 2.72 \\
\hline
\end{tabular}

${ }^{*}$ Change $=$ pre-treatment score - post treatment score; improvement if change $>0$ 


\section{Orthopedics and Rheumatology Open Access Journal}

Table 5: KOOS pain measures at baseline and 4 weeks post Physiotherapy treatment - mean change, ES, SRM.

\begin{tabular}{|c|c|c|c|c|c|c|}
\hline \multirow{2}{*}{\multicolumn{2}{|c|}{ Measure }} & \multicolumn{2}{|c|}{ Mean (SD) } & \multirow{2}{*}{$\begin{array}{c}\text { Mean (SD) } \\
\text { Change* }\end{array}$} & \multirow{2}{*}{ ES } & \multirow{2}{*}{ SRM } \\
\hline & & Pre treatment & Post treatment & & & \\
\hline \multirow{5}{*}{ KOOS } & Pain & 56.24 (13.13) & $90.76(6.20)$ & 34.52 (8.84) & 2.63 & 3.91 \\
\hline & Symptoms & $60.97(15.84)$ & 87.48 (8.79) & $26.52(9.48)$ & 1.67 & 2.8 \\
\hline & $\begin{array}{l}\text { Activities of Daily } \\
\text { Living (ADL) }\end{array}$ & $49.24(13.04)$ & 92.59 (5.77) & 43.34 (9.27) & 3.32 & 4.68 \\
\hline & $\begin{array}{c}\text { Sport and } \\
\text { Recreation } \\
\text { Function (Sport/ } \\
\text { Rec) }\end{array}$ & 25.69 (19.24) & $77.69(13.06)$ & $52(9.92)$ & 2.70 & 5.24 \\
\hline & $\begin{array}{l}\text { Quality of Life } \\
\text { (QOL) }\end{array}$ & 32.55 (12.82) & $72.52(12.51)$ & 39.97 (11.47) & 3.12 & 3.48 \\
\hline
\end{tabular}

${ }^{*}$ Change $=$ post treatment score - pre-treatment score; improvement if change $>0$.

\section{Discussion}

The Hindi ICOAP questionnaire demonstrated excellent testretest reliability, internal consistency and moderate to good correlations with KOOS pain and symptom subscales in patients with knee osteoarthritis. The study result showed that the Hindi version of ICOAP is a reliable and valid instrument for measuring pain in Hindi speaking Indian knee osteoarthritis population. The Cross-cultural adaptation process produced a Hindi version of the ICOAP scale which is simple and easy to understand by the participants like other cross-cultural adaptation version $[11,14,15]$. All the participants understood and answered all the questions which indicate the acceptability of the scale by the participants. For reliability analysis, test-retest reliability and internal consistency were assessed. High ICC values (ICC $=0.97$ 0.98 ) for the ICOAP scores indicates that the Hindi version has excellent test-retest reliability which is similar to the results for the original version (ICC=0.85), cross-culturally adapted Persian version (ICC $=0.90-0.91)$ and the Chinese version $(I C C=0.892$ 0.932) $[12,14,16]$.

A Cronbach's alpha of $\geq 0.70$ was considered satisfactory. Whereas the Cronbach's $\alpha$ values for the Hindi ICOAP scores was found between (0.85-0.912). The high Cronbach's $\alpha$ values proved satisfactory internal consistency of the Hindi ICOAP questionnaire which is similar to the original (0.93), Persian (0.92) and Turkish (0.97) internal consistency values $[12,16,17]$. In accordance with other studies the Hindi ICOAP scores exhibited good correlations with the KOOS pain and symptom scores. In the original version, ICOAP was reported to be significantly associated with KOOS symptoms subscale (Spearman's correlation coefficients of -0.60) [16]. Just like the Persian version in this study KOOS presented higher negative correlation with ICOAP scores (correlation coefficient $=-0.68$, $-0.78,-0.78$ for KOOS pain and $-0.68,-0.79,-0.80$ for KOOS symptom score with ICOAP constant, intermittent, and total pain score respectively) [15].
In the responsiveness analysis both the Hindi ICOAP and KOOS exhibited higher ES and SRM value indicating both the scales can successfully detect the change in patient's condition after 4 weeks of physiotherapy. For Hindi ICOAP scores the ES and $S R M$ values were between $E S=2.46-2.72$ and $S R M=3.37-4.38$ whereas for KOOS subscales the scores were between ES=1.673.32 and $\mathrm{SRM}=2.8-5.24$. Responsiveness study of the French KOOS subscales found similar ES= $(1.31-2.8)$ and $\mathrm{SRM}=(0.89-$ $1.93)$ in post-surgical group and in the ICOAP original version ES and $\mathrm{SRM}$ values were found $(\mathrm{ES}=0.83-1.43, \mathrm{SRM}=1.33-1.67)$ in knee OA patient receiving physiotherapy $[8,18]$. However, the ES and SRM value obtained in this study is slightly higher than those obtained in previous studies. One possible explanation of this variation may be because in this study majority of the patient was having moderate knee pain which was more responsive to treatment. Pre-treatment ceiling and floor effects were not present for the ICOAP subscales and total pain scale. Strengths of the study were the inclusion of OA participants across different levels of education, age and both male and female gender. Major limitations of the study include limited sample size of the study and responsiveness of Hindi versions of ICOAP and KOOS scales were not compared this study. In future responsiveness of both the scales can be compared in a single group of patient to find out which scale is more responsive in knee OA patient in term of pain management.

\section{Conclusion}

This study indicates that the Hindi ICOAP questionnaire is a reliable and valid instrument and it can successfully detect the change in patient's condition after 4 weeks of physiotherapy for knee osteoarthritis. So, this scale can be used as a key instrument to ensure better assessment of knee OA pain in Indian Hindi speaking population.

\section{Conflict of Interest}

There are no conflicts of interest. 


\section{Orthopedics and Rheumatology Open Access Journal}

\section{Funding/ Support}

This study received no funding support.

\section{Author's Contributions}

Study conception and design: Ovijit Baidya, Rati Prabhakar, Manni Wadhwa. Acquisition of data: Ovijit Baidya, Prosenjit Baidya. Analysis and/or interpretation of data: Ovijit Baidya, Manni Wadhwa, Prosenjit Baidya. Drafting the manuscript: Ovijit Baidya, Manni Wadhwa. Revising the manuscript critically for important intellectual content: Manni Wadhwa. Approval of the version of the manuscript to be published: Ovijit Baidya, Rati Prabhakar, Manni Wadhwa, Prosenjit Baidya.

\section{Acknowledgment}

The authors would like to thank Dr. Dheeraj Lamba, Tanvi Bhasin and Sheema Singh for their contribution in the translation and cross-cultural adaptation process of the ICOAP scale.

\section{References}

1. Maillefert JF, Kloppenburg M, Fernandes L, Punzi L, Günther KP, et al. (2009) Multi-language translation and cross-cultural adaptation of the OARSI/OMERACT measure of intermittent and constant osteoarthritis pain (ICOAP). Osteoarthritis and Cartilage 17(10): 1293-1296.

2. Chitragar DD, Shaikh SI (2016) Variables Associated with Knee Osteoarthritis in A Tertiary Care Hospital of Kanchipuram, Tamilnadu. National Journal of Medical Research 6(2): 119-123.

3. Pal CP, Singh P, Chaturvedi S, Pruthi KK, Vij A (2016) Epidemiology of knee osteoarthritis in India and related factors. Indian Journal of Orthopaedics 50(5): 518-522.

4. Das SK, Farooqi A (2008) Osteoarthritis. Best practice \& research. Clinical Rheumatology 22(4): 657-675.

5. Das SK (2012) Osteoarthritis in Wagh S. Rheumatology in Primary KYA Foundation 1(1): 13-22.

6. Steultjens MP, Dekker J, Van Baar ME, Oostendorp RA, Bijlsma JW (1999) Internal consistency and validity of an observational method for assessing disability in mobility in patients with osteoarthritis. Arthritis Care Res 12(1): 19-25.

7. Bond M, Davis A, Lohmander S, Hawker G (2012) Responsiveness of the OARSI-OMERACT osteoarthritis pain and function measures. Osteoarthritis Cartilage 20(6): 541-547.

This work is licensed under Creative Commons Attribution 4.0 License

DOI: $10.19080 /$ OROAJ.2018.10.555790
8. Gonçalves RS, Meireles AC, Gil JN, Cavalheiro LM, Rosado JO, et al. (2012) Responsiveness of intermittent and constant osteoarthritis pain (ICOAP) after physical therapy for knee osteoarthritis. Osteoarthritis and Cartilage 20(10): 1116-1119.

9. Altman R, Asch E, Bloch D, Bole G, Borenstein D, et al. (1986) Development of criteria for the classification and reporting of osteoarthritis: classification of osteoarthritis of the knee. Arthritis Rheum 29(8): 1039-1049.

10. Hawker GA, Stewart L, French MR, Cibere J, Jordan JM, et al. (2008) Understanding the pain experience in hip and knee osteoarthritis-an OARSI/OMERACT initiative. Osteoarthritis Cartilage 16(4): 415-422.

11. Erel S, Şimşek IE, Özkan H (2014) Analysis of the reliability and validity of the Turkish version of the intermittent and constant osteoarthritis pain questionnaire. Acta orthopaedica et traumatologica turcica 49(5): 508-512.

12. Turner KV, Moreton BM, Walsh DA, Lincoln NB (2017) Reliability and responsiveness of measures of pain in people with osteoarthritis of the knee: a psychometric evaluation. Disability and Rehabilitation 39(8): 822-829.

13. Cheung RT, Ngai SP, Ho KK (2016) Chinese adaptation and validation of the Knee Injury and Osteoarthritis Outcome Score (KOOS) in patients with knee osteoarthritis. Rheumatology International. 36(10): 14491454.

14.Zhang C, Liu DH, Qu YL, Jia ZY, Wang W, et al. (2017) Transcultural adaptation and validation of the Chinese version of the intermittent and constant osteoarthritis pain (ICOAP) measure in patients with knee osteoarthritis. Osteoarthritis Cartilage 25(4): 506-512.

15. Panah SH, Baharlouie H, Rezaeian ZS, Hawker G (2016) Cross-cultural adaptation and validation of the Persian version of the Intermittent and Constant Osteoarthritis Pain Measure for the knee. Iran J Nurs Midwifery Res 21(4): 417-423.

16. Hawker GA, Davis AM, French MR, Cibere J, Jordan JM, et al. (2008) Development and preliminary psychometric testing of a new OA pain measure-an OARSI/OMERACT initiative. Osteoarthritis Cartilage 16(4): 409-44.

17. Moutzouri M, Tsoumpos P, Billis E, Papoutsidakis A, Gliatis J (2015) Cross-cultural translation and validation of the Greek version of the Knee Injury and Osteoarthritis Outcome Score (KOOS) in patients with total knee replacement. Disability and Rehabilitation 37(16): 14771483.

18. Ornetti P, Parratte S, Gossec L, Tavernier C, Argenson JN, et al. (2008) Cross-cultural adaptation and validation of the French version of the Knee injury and Osteoarthritis Outcome Score (KOOS) in knee osteoarthritis patients. Osteoarthritis and Cartilage 16(4): 423-428.

\section{Your next submission with Juniper Publishers will reach you the below assets}

- Quality Editorial service

- Swift Peer Review

- Reprints availability

- E-prints Service

- Manuscript Podcast for convenient understanding

- Global attainment for your research

- Manuscript accessibility in different formats

( Pdf, E-pub, Full Text, Audio)

- Unceasing customer service

Track the below URL for one-step submission https://juniperpublishers.com/online-submission.php 